\title{
A Novel and Severe Clinical Picture Related to COVID-19: Multi-Inflammatory Syndrome in Children
}

\author{
Fatih Haşlak ${ }^{\oplus}$, Mehmet Yıldız $\odot$, Sezgin Şahin $\odot$, Amra Adrovic $\oplus^{\oplus}$, Kenan Barut $\odot$ \\ Özgür Kasapçopur $\odot$
}

Istanbul University-Cerrahpaşa Cerrahpaşa Medical School, Department of Pediatric Rheumatology, İstanbul, Turkey

Cite as: Haşlak F, Yıldız M, Şahin S, Adrovic A, Barut K, Kasapçopur Ö. A novel and severe clinical picture related to COVID-19: multi-inflammatory syndrome in children. Trends in Pediatrics 2021;2(2):51-9.

Received: 20 April 2021

Accepted: 01 June 2021

Publication date: 29 June 2021

Keywords: SARS-CoV-2, COVID-19, MIS-C, rheumatology, pediatric intensive care unit

Özgür Kasapçopur

İstanbul Üniversiesi-Cerrahpaşa Cerrahpaşa Tıp Fakültesi Yerleşkesi Kocamustafapaşa Cad. No: 53 Cerrahpaşa 34098 Fatih, Istanbul, Turkey

ORCID: 0000-0002-1125-7720

ozgurkasapcopur@hotmail.com

F. Haslak 0000-0002-6963-9668

M. Yıldız 0000-0002-7834-4909

S. Şahin 0000-0002-5365-3457

A. Adrovic 0000-0002-2400-6955

K. Barut 0000-0001-8459-2872

\section{ABSTRACT}

Preliminary data have suggested that children have milder COVID19 disease course compared to adults. However, pediatric cases with severe clinical findings caused by Severe Acute Respiratory Syndrome Coronavirus-2 (SARS-CoV-2) are being reported since April 2020. These children have been presented with significant hyperinflammatory states resembling Kawasaki disease, toxic shock syndrome, and macrophage activation syndrome. However, they had several distinct features, as well. Therefore, this novel condition was considered a unique disease and named Multiinflammatory syndrome in children (MIS-C). Thus, new concerns have been raised regarding the vulnerability of the children. However, it has been realized that this condition is extremely rare. Nonetheless, considering that it is a life-threatening disease and may cause devastating consequences, clinicians should be aware of MIS-C while evaluating children with persistent fever and history of COVID-19 contact or active infection.

\section{INTRODUCTION}

In December 2019, a cluster of pneumonia cases with atypical and severe symptoms emerged in Wuhan Province of China. Due to the distinct clinical features of these patients, advanced laboratory investigations were performed, and a novel coronavirus named severe acute respiratory syndrome coronavirus 2 (SARS-CoV-2) was isolated for the first time. The disease caused by the virus was also novel and named coronavirus disease 2019 (COVID-19). Then, the virus spread worldwide, and due to the rapidly increasing number of patients,
World Health Organization declared this outbreak as a global pandemic on March 11, 2020. ${ }^{1}$

The clinical findings of COVID-19 range in a large scale between an asymptomatic carriage and severe presentations such as acute respiratory syndrome (ARDS) and multiorgan dysfunction..$^{2,3}$ Fortunately, early data revealed that children have a milder disease course and better prognosis compared to adults. ${ }^{4,5}$ Thus, the idea of the children is almost not affected by the pandemic was prevalent. Families did not sufficiently insist on their children wearing a mask or keeping the social distance, and several 
governments loosened the school attendance restrictions.

However, this positive discrimination in favor of children provided by the virus did not last so long. In April 2020, SARS-CoV-2 was isolated from eight children with suggestive symptoms of Kawasaki disease (KD), such as fever, conjunctivitis, and peripheral edema. In addition to KD- resembling features, those children had gastrointestinal symptoms such as vomiting and diarrhea and developed refractory shock. ${ }^{6}$ Subsequently, it has been shown that SARS-CoV-2 may also induce a hyperinflammatory state in children resembling toxic shock syndrome (TSS) and macrophage activation syndrome (MAS) rather than KD. ${ }^{7,8}$ Therefore, the Centers for Disease Control and Prevention (CDC) recognized this SARS-CoV-2-induced hyperinflammatory condition as a novel disease and named it as multisystem inflammatory syndrome in children (MIS-C). ${ }^{9}$

Recent findings regarding MIS-C suggest that children are not thought to have host advantages against SARS-CoV-2 as much as previously considered. Therefore, in this review article, we aimed to contribute to a better understanding of this novel disease.

\section{Epidemiology}

A male dominance among the patients was shown in several studies. ${ }^{10-12}$ A systematic review evaluating 917 MIS-C patients showed that the median age of the patients was 9.3 years, and $56.8 \%$ of the cases were males. ${ }^{13}$ Similarly, male/female ratio was $1.37: 1$, and the median age was 7.5 years in another systematic review including 992 MIS-C patients. ${ }^{14}$ It is well known that the current pandemic was originated from East Asia. Besides, KD is in the differential diagnosis of MIS-C mostly seen in Asian children. ${ }^{15}$ On the contrary, there is an Afro-Caribbean and Hispanic ethnic predominance among the MIS-C patients. ${ }^{16}$ These intriguing findings make us consider that a genetic predisposition or environmental circumstances may play a pivotal role in the pathogenesis of MIS-C.

\section{Pathogenesis}

Although it has not been precisely elucidated yet, there are several suggested mechanisms for explaining the pathogenesis of MIS-C. Children diagnosed as MIS-C usually have contracted SARSCoV-2 infection two to four weeks before the onset of MIS-C symptoms. ${ }^{17}$ There is an overall four-week interval between the date of the peak incidence of the outbreak and the date of the observation of MIS-C patients for the first time. ${ }^{18-21}$ Besides, it has been demonstrated in several studies that positive antibody testing is much more common than polymerase-chain reaction (PCR) test positivity among MIS-C patients. ${ }^{22-24}$ These findings strongly suggest that a post-infectious process rather than a direct viral invasion is responsible for the pathogenesis of the disease.

There are also conflicting hypotheses. For instance, a decreased SARS-CoV-2 antibody activity in patients with MIS-C compared to COVID-19 patients has been recently shown. Therefore, a persistent infection was speculated to be the main pathogenic mechanism instead of a post-infectious syndrome. ${ }^{25}$ Consistently, Colmenero et al. ${ }^{26}$ demonstrated viroid particles of SARS-CoV-2 in the skin biopsies of seven children who presented with chilblain four weeks after the peak incidence of the outbreak in their geographical region, similar to the MIS-C patients.

Since there are several clinical similarities between TSS and MIS-C, studies focused on investigating the molecular proof of this similarity have been also performed. ${ }^{27}$ It is already known that staphylococcal enterotoxin B (SEB) has a superantigen (SAg) motif, and this motif causes host-cell damage via inducing a massive release of inflammatory cytokines. ${ }^{28}$ Similar to SEB, SARS-CoV-2 has also been shown to encode a protein that shares remarkable sequential and structural similarities with SAgs..$^{29,30}$

A study evaluating 58 MIS-C patients reported that while the PCR test was negative in most of their patients, SARS-CoV-2 antibody test results were positive. Besides, majority of them had significantly elevated inflammatory markers, and anakinra (antiIL-1 agent) and achieved a prominent clinical improvement. Therefore, they suggested that the possible mechanism of action of the disease is an exacerbated post-infectious hyperinflammatory response. $^{31}$ 
Similarly, most of the patients presented with cardiac signs and increased inflammatory markers, and as reported by Kaushik et al. ${ }^{32}$ they had antibody positivity against SARS-CoV-2. Given that there is no strong evidence for the cardiac tropism of the virus, they proposed that an antibody-induced cytokine storm may be responsible for the tissue damage.

\section{Clinical features}

The first cases with SARS-CoV-2- induced hyperinflammation were reported by Riphagen et al. ${ }^{6}$ from the United Kingdom (UK). As it was mentioned before, the patients all had KD- like symptoms such as fever, conjunctivitis, peripheral edema, and extremity pain. Moreover, they had gastrointestinal features such as diarrhea, vomiting, and abdominal pain. However, none of them had significant respiratory involvement. One of the patients who developed cardiac dysrhythmia and received extracorporeal membrane oxygenation (ECMO) therapy unfortunately died. An unclear linkage between KD and SARS-CoV-2 was emerged.

Following this study from the UK, Chiotos et al. ${ }^{33}$ described six patients with MIS-C. Similarly, they had KD-like features, gastrointestinal symptoms, and shock. Among ten MIS-C patients reported from Italy, in addition to KD-like symptoms such as fever, rashes, conjunctivitis, mucositis, and lymphadenopathy, the patients had diarrhea (n:6), hypotension ( $\mathrm{n}: 5)$, pneumonia ( $\mathrm{n}: 5)$, and meningeal signs (n:4).22

However, subsequently reported cases with SARSCoV-2- induced hyperinflammation had distinct aspects from the KD. Rather than the KD, given the clinical and laboratory similarities such as fever, refractory shock, organ damage signs, and complete blood count, cytokine, inflammatory markers, and lipid profiles, TSS and MAS were also emphasized in the differential diagnosis of MIS-C, as well. ${ }^{17,34,35}$

In the study which reported the first MIS-C cases from New York City, although all the patients were seropositive, only seven of fifteen cases had a positive PCR result. While all the patients had fever, the patients also had severe cardiac involvement ( $n: 13)$, gastrointestinal features (n:13), skin changes $(n: 7)$, respiratory involvement $(n: 7)$, conjunctivitis
( $n: 4)$, peripheral edema ( $\mathrm{n}: 4)$, and 9 cases required treatment with inotropic or vasopressor agents. Levels of acute phase reactants increased in most of them, whereas platelets, lymphocytes, and serum albumin levels decreased. ${ }^{36}$

It was shown in a retrospective study that following the fever, the most common symptoms among MIS-C patients were gastrointestinal involvement, conjunctivitis, erythematous rash, and oral changes. ${ }^{37}$ A study from Turkey, including 36 MIS-C patients, reported that the most common symptoms were fever, mucocutaneous rashes, and gastrointestinal symptoms, respectively. ${ }^{38}$ Fever and abdominal pain were the most common symptoms in a study of Tolunay et al. ${ }^{39}$ The first report regarding the MIS-C from East Mediterranean Region compared COVID19 and MIS-C and revealed that the patients with MIS-C had a higher duration of fever and higher rates of rashes and conjunctivitis. ${ }^{40}$

According to a systematic review article, the most common clinical findings out of fever were as follows: gastrointestinal (87\%), muco-cutaneous (73\%), cardiovascular (71\%), respiratory (47\%), neurological (22\%), and musculoskeletal (21\%) symptoms. ${ }^{16}$ Similarly, it has been revealed in a more current systematic review that the two most common symptoms of MIS-C patients were fever and gastrointestinal symptoms. ${ }^{16}$

It was previously mentioned that MIS-C mainly occurs in school-age children and adolescents. However, there is a recent paper describing ten infants with MIS-C. Unlike seen in older ones, the most common finding other than fever was rashes. Five patients had respiratory distress, and one had febrile convulsion. Unfortunately, two with congenital heart diseases died. ${ }^{41}$

Considering the underlying pathogenic mechanism of MIS-C, in addition to TSS, MAS, and KD- like symptoms, a variety of organ damage or inflammation signs are already expected. For instance, several MIS-C patients initially presented with acute abdomen- like signs such as acute appendicitis. ${ }^{42,43}$ Furthermore, it is well known that MIS-C patients may have severe cardiac compromise at high rates that can be considered life-threatening events. ${ }^{44}$ 
Therefore, to prevent unnecessary surgical operations during the pandemic, it has been suggested that pediatric surgeons perform a myocardial evaluation and rule out the MIS-C in children who presented with acute abdomen. ${ }^{45}$

Although any segment of the gastrointestinal tract can be compromised, there is a predominance of ileal and colonic inflammation among the patients. Progressive bowel obstruction which mainly recovers with medical treatment may occur. However, a minority of the cases may require surgical resections. ${ }^{46}$

In a retrospective study, acute kidney injury (AKI) was seen in ten of fifty-five MIS-C patients. AKI developed at admission in most of them which were associated with lower serum albumin levels and higher white blood cell counts. ${ }^{47}$

Two out of 9 MIS-C patients recently reported from Germany had unusual findings. One developed encephalomyelitis. The other had been newly diagnosed with acute leukemia, just a few weeks after the onset of SARS-CoV-2 infection. Two days after the chemotherapy, this male patient had a sudden respiratory failure and was diagnosed as MIS-C in the intensive care unit. However, it remains unclear whether chemotherapy or the virus triggered leukemia. ${ }^{48}$

Thirty-five patients admitted to the pediatric intensive care unit due to acute heart failure and hyperinflammatory condition were evaluated in a multicenter study, and SARS-CoV-2 infection was proven in thirty-one of them. ${ }^{49}$ Furthermore, Stevens et al. ${ }^{50}$ reported a MIS-C patient who initially presented with acute pancreatitis, and Kashyap et al. ${ }^{51}$ reported a seven-month-old patient with MIS-Crelated status epilepticus.

We also encountered children with MIS-C in our daily practice. There was a slight male predominance, and cases were mostly school-age children and adolescents, similar to the current literature. ${ }^{13,14}$ While the PCR tests were negative in most of them, they were seropositive against SARS-CoV-2. Fever and gastrointestinal symptoms were the most common symptoms. Although not pointed out before, rashes of our patients were mostly welldemarcated and round shaped. We presented rashes of some of our patients below (Figure 1). Thrombocytopenia, lymphopenia, abnormal cardiac enzymes, and elevated acute phase reactants were the most common laboratory findings. Overall, one third of the patients required intensive care due to respiratory failure or other severe organ damages. All but one recovered completely. Unfortunately, one patient who previously received the diagnosis of acute lymphoblastic leukemia died.

\section{Diagnosis}

Considering the similarities and differences between the hyperinflammatory conditions caused by SARSCoV-2, and KD, TSS, and MAS, this novel entity was considered to be a unique disease by $\mathrm{CDC}$, and its diagnostic criteria were established (Table 1).9,52

\section{Table 1. Diagnostic criteria of MIS-C}

\section{Case Definition for MIS-C (48)}

- An individual aged $<21$ years presenting with fevera, laboratory evidence of inflammationb, and evidence of clinically severe illness requiring hospitalization, with multisystem ( $\geq 2$ ) organ involvement (cardiac, renal, respiratory, hematologic, gastrointestinal, dermatologic, or neurological); AND

- No alternative plausible diagnoses; AND

- Positive for current or recent SARS-CoV-2 infection by RT-PCR, serology, or antigen test or COVID-19 exposure within the four weeks before the onset of symptoms.

COVID-19, coronavirus disease 2019; IL, interleukin; MIS-C, multisystem inflammatory syndrome in children; RT-PCR, reverse transcriptase polymerase chain reaction; SARS-CoV-2, severe acute respiratory syndrome coronavirus 2.

a Fever $\geq 38.0^{\circ} \mathrm{C}$ for $\geq 24$ hours or report of subjective fever lasting $\geq 24$ hours.

$b$ Including, but not limited to, one or more of the following: an elevated C-reactive protein, erythrocyte sedimentation rate, fibrinogen, procalcitonin, d-dimer, ferritin, lactic acid dehydrogenase, or IL-6; elevated neutrophils; reduced lymphocytes; and low albumin. 

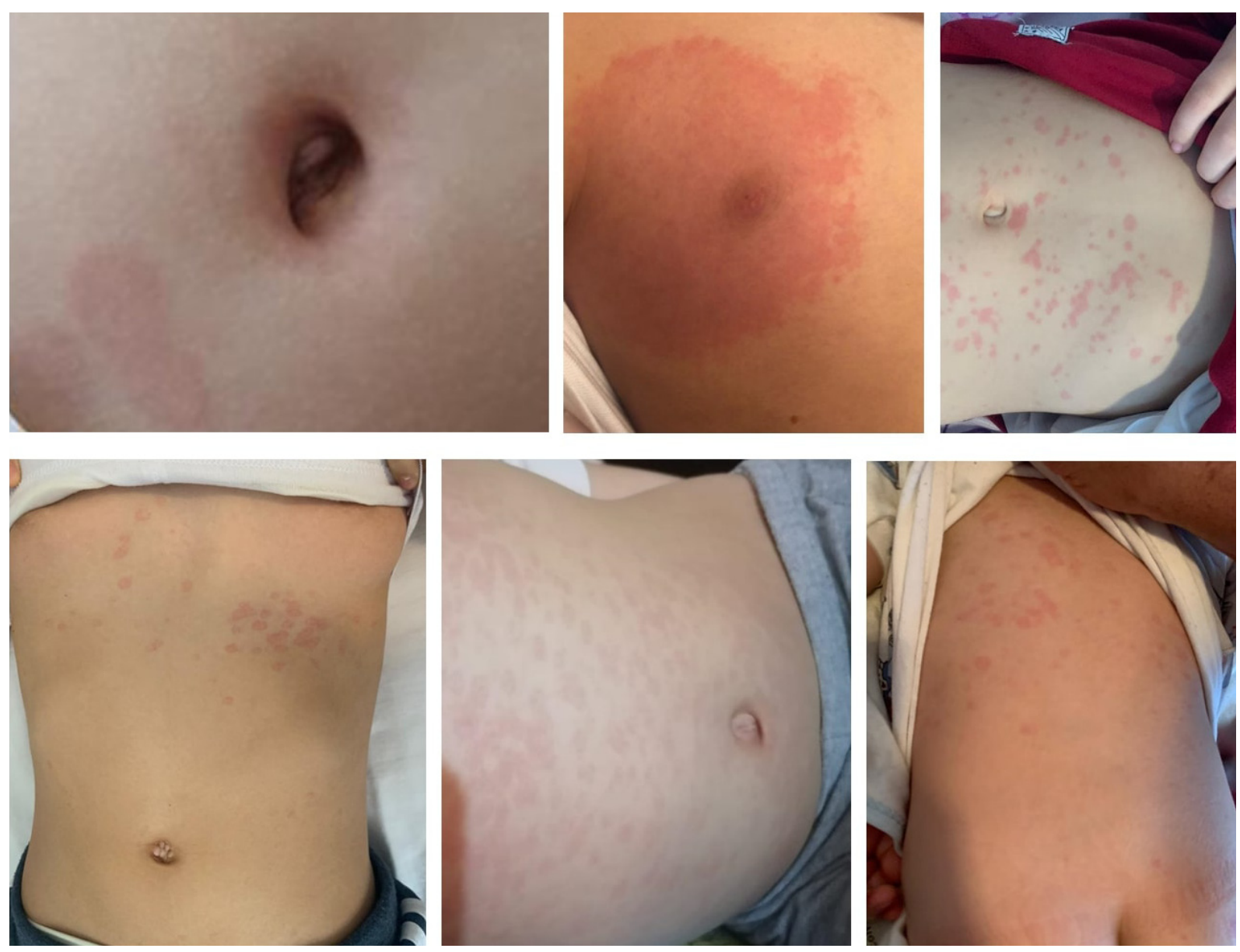

Figure 1. The rashes seen in some of our MIS-C patients

\section{Treatment}

Since highly suggestive symptoms for KD are seen in patients with MIS-C, early cases were treated with intravenous immunoglobulin (IVIG) and acetylsalicylic acid similar to the patients with KD, and favorable outcomes have been achieved..$^{6,49,53}$ Moreover, immunomodulatory treatment options such as anakinra and tocilizumab were given to IVIG and steroid non-responders which were found to be highly effective. ${ }^{31,32,53}$

Given that the MIS-C is a hyperinflammatory condition, steroids were widely used based on their well-known strong anti-inflammatory effects although their safety and efficacy remain unclear. ${ }^{17}$ In a study from Istanbul, seven of twenty MIS-C patients required intensive care. While IVIG responses of the patients were inadequate, steroids were observed to have a dramatic effect. ${ }^{54}$
In our daily practice, all patients with MIS-C are initially given IVIG at a dose of $2 \mathrm{gr} / \mathrm{kg}$ as the first-line treatment. If there is shock or organ threatening event, methylprednisolone $(1-2 \mathrm{mg} / \mathrm{kg} /$ day) is added. To the refractory cases, methylprednisolone (10-30 $\mathrm{mg} / \mathrm{kg} /$ day) or high dose anakinra is given as the second-line treatment. Moreover, all of the MIS-C patients receive acetylsalicylic acid unless active bleeding or platelet count is lower than 80 000/ $\mathrm{mm}^{3} .{ }^{55}$ Plasmapheresis is performed in patients with resistance to medical treatment options in our center, and most of our refractory cases clinically have improved so far. We tried to summarize schematically our therapeutic approach (Figure 2).

In a study from the United States, infliximab (an antitumor necrosis factor-alpha agent) was given to 12 of 13 IVIG and steroid non-responder MIS-C patients, and all of them recovered. ${ }^{56}$ Consistently, as recently 


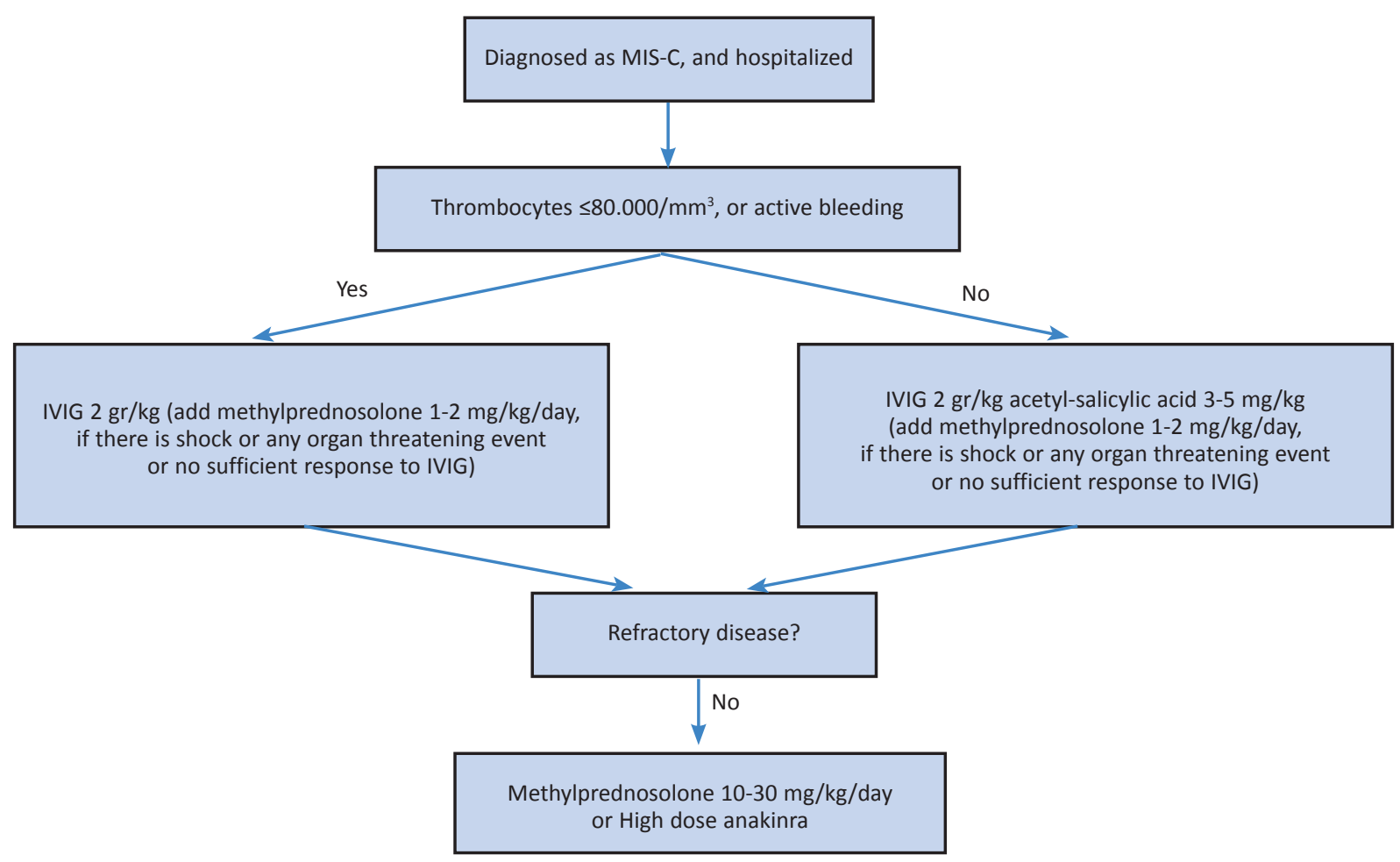

Figure 2. Our therapeutic approach for the MIS-C

reported by Alkan et al. ${ }^{57}$ the authors had given infliximab to a MIS-C patient with underlying inflammatory bowel disease, and they achieved clinical recovery.

Although there is insufficient data regarding the safety and effectiveness of highly invasive procedures such as ECMO, they may be performed in medically intractable MIS-C patients. ${ }^{58}$

\section{CONCLUSION}

In conclusion, MIS-C is a less understood, rare, and highly fatal complication of COVID-19. Given the recent data regarding MIS-C, children are not thought to be in a favorable position during the pandemic as was presumed previously. Clinicians should be aware of this novel disease while evaluating children with persistent fever and history of COVID-19 contact or active infection. Since the clinical signs may rapidly deteriorate in these patients, medical treatment should be promptly started if there is a diagnostic suspicion. Besides, it has been recently seen that these patients could present with many distinct clinical pictures such as acute appendicitis or pancreatitis. Therefore, particularly in these extraordinary days, MIS-C should always be kept in mind for children with unusual signs and symptoms.

Conflict of Interest: The authors have no conflicts of interest to declare.

Financial Disclosure: The authors declared that this study has received no financial support.

\section{REFERENCES}

1. Haslak F, Yildiz M, Adrovic A, et al. Management of childhood-onset autoinflammatory diseases during the COVID-19 pandemic. Rheumatol Int. 2020;40:142331. https://doi.org/10.1007/s00296-020-04645-x

2. Singhal T. A Review of Coronavirus Disease-2019 (COVID-19). Indian J Pediatr. 2020;87:281-6. https://doi.org/10.1007/s12098-020-03263-6

3. Haşlak F, Yıldız M, Adrovic A, Barut K, Kasapçopur Ö. Childhood rheumatic diseases and COVID-19 pandemic: An Intriguing linkage and a new horizon. Balkan Med J. 2020;37:184-8. https://doi.org/10.4274/balkanmedj.galenos.2020. 2020.4.43

4. Ludvigsson JF. Systematic review of COVID-19 in children shows milder cases and a better prognosis than adults. Acta Paediatr. 2020;109:1088-95. 
https://doi.org/10.1111/apa.15270

5. Wu Z, McGoogan JM. Characteristics of and important lessons from the coronavirus disease 2019 (COVID-19) outbreak in China: Summary of a Report of 72314 cases from the Chinese center for disease control and prevention. Jama. 2020;323:1239-42. https://doi.org/10.1001/jama.2020.2648

6. Riphagen S, Gomez X, Gonzalez-Martinez C, Wilkinson $\mathrm{N}$, Theocharis P. Hyperinflammatory shock in children during COVID-19 pandemic. Lancet. 2020;395:1607-8. https://doi.org/10.1016/S0140-6736(20)31094-1

7. Panupattanapong $S$, Brooks EB. New spectrum of COVID-19 manifestations in children: Kawasaki-like syndrome and hyperinflammatory response. Cleve Clin J Med. 2020.

https://doi.org/10.3949/ccjm.87a.ccc039

8. Schvartz A, Belot A, Kone-Paut I. Pediatric Inflammatory Multisystem syndrome and rheumatic diseases during SARS-CoV-2 pandemic. Front Pediatr. 2020;8:605807. https://doi.org/10.3389/fped.2020.605807

9. Bhat CS, Gupta L, Balasubramanian S, Singh S, Ramanan AV. Hyperinflammatory syndrome in children üssociated With COVID-19: Need for üwareness. Indian Pediatr. 2020;57:929-35. https://doi.org/10.1007/s13312-020-1997-1

10. Aydın F, Çelikel E, Ekici Tekin Z, et al. Comparison of baseline laboratory findings of macrophage activation syndrome complicating systemic juvenile idiopathic arthritis and multisystem inflammatory syndrome in children. Int J Rheum Dis. 2021;24:542-7. https://doi.org/10.1111/1756-185X.14078

11. Emeksiz S, Özcan S, Perk O, et al. Therapeutic plasma exchange: A potential management strategy for critically ill MIS-C patients in the pediatric intensive care unit. Transfus Apher Sci. 2021:103119. https://doi.org/10.1016/j.transci.2021.103119

12. Çelikel E, Tekin ZE, Aydin F, et al. Role of Biological Agents in the Treatment of SARS-CoV-2-Associated Multisystem Inflammatory Syndrome in Children. J Clin Rheumatol. 2021. https://doi.org/10.1097/RHU.0000000000001734

13. Yasuhara J, Watanabe $\mathrm{K}$, Takagi $\mathrm{H}$, Sumitomo $\mathrm{N}$, Kuno $\mathrm{T}$. COVID-19 and multisystem inflammatory syndrome in children: A systematic review and meta-analysis. Pediatr Pulmonol. 2021;56:837-48. https://doi.org/10.1002/ppul.25245

14. Sood M, Sharma S, Sood I, Sharma K, Kaushik A. Emerging avidence on multisystem enflammatory syndrome in children üssociated with SARS-CoV-2 enfection: a Systematic review with meta-analysis. SN Compr Clin Med. 2021:1-10. https://doi.org/10.1007/s42399-020-00690-6

15. Lin MT, Wu MH. The global epidemiology of Kawasaki disease: Review and future perspectives. Glob Cardiol Sci Pract. 2017; 2017:e201720. https://doi.org/10.21542/gcsp.2017.20

16. Abrams JY, Godfred-Cato SE, Oster ME, et al. Multisystem inflammatory syndrome inchildren associated with severe acute respiratory syndrome coronavirus 2: A Systematic review. J Pediatr. 2020;226:45-54.e1. https://doi.org/10.1016/j.jpeds.2020.08.003

17. Simon Junior $H$, Sakano TMS, Rodrigues RM, et al. Multisystem inflammatory syndrome associated with
COVID-19 from the pediatric emergency physician's point of view. J Pediatr (Rio J). 2021;97:140-59. https://doi.org/10.1016/j.jped.2020.08.004

18. Koné-Paut I, Cimaz R. Is it Kawasaki shock syndrome, Kawasaki-like disease or pediatric inflammatory multisystem disease? The importance of semantic in the era of COVID-19 pandemic. RMD Open. 2020;6:e001333.

https://doi.org/10.1136/rmdopen-2020-001333

19. Waltuch T, Gill P, Zinns LE, et al. Features of COVID-19 post-infectious cytokine release syndrome in children presenting to the emergency department. Am J Emerg Med. 2020;38:2246.e3-2246.e6.

https://doi.org/10.1016/j.ajem.2020.05.058

20. Grimaud M, Starck J, Levy M, et al. Acute myocarditis and multisystem inflammatory emerging disease following SARS-CoV-2 infection in critically ill children. Ann Intensive Care. 2020;10:69. https://doi.org/10.1186/s13613-020-00690-8

21. Belot A, Antona D, Renolleau S, et al. SARS-CoV-2related paediatric inflammatory multisystem syndrome, an epidemiological study, France, 1 March to 17 May 2020. Euro Surveill. 2020;25:2001010. https://doi.org/10.2807/1560-7917.ES.2020.25.22. 2001010

22. Verdoni L, Mazza A, Gervasoni A, et al. An outbreak of severe Kawasaki-like disease at the Italian epicentre of the SARS-CoV-2 epidemic: an observational cohort study. Lancet. 2020;395:1771-8. https://doi.org/10.1016/S0140-6736(20)31103-X

23. Toubiana J, Poirault C, Corsia A, et al. Kawasaki-like multisystem inflammatory syndrome in children during the covid-19 pandemic in Paris, France: prospective observational study. BMJ. 2020;369:m2094. https://doi.org/10.1136/bmj.m2094

24. Cheung EW, Zachariah P, Gorelik M, et al. Multisystem inflammatory syndrome related to COVID-19 in previously healthy children and adolescents in New York City. Jama. 2020;324:294-6. https://doi.org/10.1001/jama.2020.10374

25. Schwartz M. MIS-C: post-infectious syndrome or persistent infection? Lancet Infect Dis. 2021;21:e116. https://doi.org/10.1016/S1473-3099(20)30786-6

26. Colmenero I, Santonja C, Alonso-Riaño M, et al. SARSCoV-2 endothelial infection causes COVID-19 chilblains: histopathological, immunohistochemical and ultrastructural study of seven paediatric cases. $\mathrm{Br} \mathrm{J}$ Dermatol. 2020;183:729-37. https://doi.org/10.1111/bjd.19327

27. Haslak F, Yıldız M, Adrovic A, Şahin S, Barut K, Kasapçopur Ö. A recently explored aspect of the iceberg named COVID-19: multisystem inflammatory syndrome in children (MIS-C). Turk Arch Pediatr. 2021;56:3-9.

28. Plaza R, Rodriguez-Sanchez JL, Juarez C. Staphylococcal enterotoxin $B$ in vivo modulates both gamma interferon receptor expression and ligand-induced activation of signal transducer and activator of transcription 1 in $T$ cells. Infect Immun. 2007;75:306-13. https://doi.org/10.1128/IAI.01220-06

29. Bittmann S, Weissenstein A, Villalon G, MoschuringAlieva E, Luchter E. Simultaneous treatment of COVID19 with serine protease inhibitor camostat and/or cathepsin L inhibitor? J Clin Med Res. 2020;12:320-2. 
https://doi.org/10.14740/jocmr4161

30. Cheng $\mathrm{MH}$, Zhang S, Porritt RA, et al. Superantigenic character of an insert unique to SARS-CoV-2 spike supported by skewed TCR repertoire in patients with hyperinflammation. Proc Natl Acad Sci U S A. 2020;117:25254-62. https://doi.org/10.1073/pnas.2010722117

31. Whittaker E, Bamford A, Kenny J, et al. Clinical Characteristics of 58 children with a pediatric inflammatory multisystem syndrome temporally associated with SARS-CoV-2. Jama. 2020;324:259-69. https://doi.org/10.1001/jama.2020.10369

32. Kaushik S, Aydin SI, Derespina KR, et al. Multisystem inflammatory syndrome in children associated with severe acute respiratory syndrome coronavirus 2 infection (MIS-C): A multi-institutional study from New York city. J Pediatr. 2020;224:24-9. https://doi.org/10.1016/j.jpeds.2020.06.045

33. Chiotos K, Bassiri H, Behrens EM, et al. Multisystem inflammatory syndrome in children during the coronavirus 2019 pandemic: A case series. J Pediatric Infect Dis Soc. 2020;9:393-8. https://doi.org/10.1093/jpids/piaa069

34. Nguyen DC, Haydar H, Pace ER, Zhang XS, Dobbs KR. Pediatric case of severe COVID-19 with shock and multisystem inflammation. Cureus. 2020;12:e8915. https://doi.org/10.7759/cureus.8915

35. Greene AG, Saleh M, Roseman E, Sinert R. Toxic shocklike syndrome and COVID-19: Multisystem inflammatory syndrome in children (MIS-C). Am J Emerg Med. 2020;38:2492.e5-.e6. https://doi.org/10.1016/j.ajem.2020.05.117

36. Riollano-Cruz $M$, Akkoyun $E$, Briceno-Brito $E$, et al. Multisystem inflammatory syndrome in children related to COVID-19: A New York City experience. J Med Virol. 2021;93:424-33. https://doi.org/10.1002/jmv.26224

37. Başar EZ, Sönmez HE, Öncel S, Yetimakman AF, Babaoğlu $\mathrm{K}$. Multisystemic inflammatory syndrome in children associated with COVID-19: a single center experience in Turkey. Turk Arch Pediatr. 2021;56:192-9. https://doi.org/10.5152/TurkArchPediatr.2021.21018

38. Alkan G, Sert A, Oz SKT, Emiroglu M, Yılmaz R. Clinical features and outcome of MIS-C patients: an experience from Central Anatolia. Clin Rheumatol. 2021:1-11. https://doi.org/10.1007/s10067-021-05754-z

39. Tolunay O, Çelik Ü, Arslan İ, et al. Multisystem inflammatory syndrome in Children (MIS-C) Associated with COVID-19: A case series experience in a tertiary care hospital of southern Turkey. J Trop Pediatr. 2021;67:fmab050. https://doi.org/10.1093/tropej/fmab050

40. Ozsurekci Y, Gürlevik S, Kesici S, et al. Multisystem inflammatory syndrome in children during the COVID19 pandemic in Turkey: first report from the Eastern Mediterranean. Clin Rheumatol. 2021:1-11. https://doi.org/10.1007/s10067-021-05631-9

41. Yurttutan S, Güllü UU, İpek S, Gungor S, Yurttutan N. Clinical and laboratory findings of multisystem inflammatory syndrome in children (MIS-C) below age 1. Clin Rheumatol. 2021:1-2. https://doi.org/10.1007/s10067-021-05706-7

42. Jackson RJ, Chavarria HD, Hacking SM. A case of multisystem inflammatory syndrome in children mimicking acute appendicitis in a COVID-19 pandemic Area. Cureus. 2020;12:e10722.

https://doi.org/10.7759/cureus.10722

43. Tullie L, Ford K, Bisharat M, et al. Gastrointestinal features in children with COVID-19: an observation of varied presentation in eight children. Lancet Child Adolesc Health. 2020;4:e19-e20. https://doi.org/10.1016/S2352-4642(20)30165-6

44. Álvarez ZP, Larios GG, Toro RL, et al. Recommendation for the recognition, management and follow up of cardiovascular compromise in patients with Pediatric Multisystemic Inflammatory Syndrome associated with COVID-19 (PIMS-CT). Position statement of Chilean Scientific Societies. Rev Chil Pediatr. 2020;91:982-90. https://doi.org/10.32641/rchped.v91i6.3215

45. Valitutti F, Verde A, Pepe A, et al. Multisystem inflammatory syndrome in children. An emerging clinical challenge for pediatric surgeons in the COVID 19 era. J Pediatr Surg Case Rep. 2021;69:101838. https://doi.org/10.1016/j.epsc.2021.101838

46. Sahn B, Eze OP, Edelman MC, et al. Features of intestinal disease associated with COVID-related multisystem inflammatory syndrome in Children. J Pediatr Gastroenterol Nutr. 2021;72:384-7. https://doi.org/10.1097/MPG.0000000000002953

47. Basalely A, Gurusinghe S, Schneider J, et al. Acute kidney injury in pediatric patients hospitalized with acute COVID-19 and multisystem inflammatory syndrome in children associated with COVID-19. Kidney Int. 2021;100:138-45 https://doi.org/10.1016/j.kint.2021.02.026

48. Mehler K, Jung N, Oberthuer A. Is it all MIS-C? Unusual findings in a series of nine German patients with multisystem inflammatory syndrome in children after SARSCoV-2 infection. Int J Infect Dis. 2021;106:405-8. https://doi.org/10.1016/j.ijid.2021.04.044

49. Belhadjer Z, Méot M, Bajolle F, et al. Acute heart failure in multisystem inflammatory syndrome in children in the context of global SARS-CoV-2 pandemic. Circulation. 2020;142: 429-36. https://doi.org/10.1161/CIRCULATIONAHA.120.048360

50. Stevens JP, Brownell JN, Freeman AJ, Bashaw H. COVID19-associated Multisystem Inflammatory Syndrome in Children Presenting as Acute Pancreatitis. J Pediatr Gastroenterol Nutr. 2020;71:669-71. https://doi.org/10.1097/MPG.0000000000002860

51. Kashyap H, Gupta V, Gupta A, Gupta T, Sharma S, Valjiyani S. Post-COVID Syndrome (MIS-C) with refractory status epilepticus. Indian J Pediatr. 2021:1. https://doi.org/10.1007/s12098-021-03731-7

52. CDC Health Alert Network. Multisystem Inflammatory Syndrome in Children (MIS-C) Associated with Coronavirus Disease 2019 (COVID-19). Available online: https://emergency.cdc.gov/han/2020/han00432.asp (accessed on 12 May 2021).

53. Miller J, Cantor A, Zachariah P, Ahn D, Martinez M, Margolis KG. Gastrointestinal Symptoms as a Major Presentation Component of a Novel Multisystem Inflammatory Syndrome in Children That Is Related to Coronavirus Disease 2019: A Single Center Experience of 44 Cases. Gastroenterology. 2020;159:1571-4. https://doi.org/10.1053/j.gastro.2020.05.079

54. Öcal Demir S, Tosun Ö, Öztürk K, Duyu M, et al. SARSCoV-2 associated multisystem inflammatory syndrome 
in children (MIS-C). A single center's experience. Minerva Pediatr (Torino). 2021.

55. Henderson LA, Canna SW, Friedman KG, et al. American college of rheumatology clinical guidance for multisystem inflammatory syndrome in children Associated with SARS-CoV-2 and hyperinflammation in Pediatric COVID-19: Version 2. Arthritis Rheumatol. 2021;73:e13-e29.

https://doi.org/10.1002/art.41616

56. Abdel-Haq N, Asmar BI, Deza Leon MP, et al. SARS-CoV2-associated multisystem inflammatory syndrome in children: clinical manifestations and the role of infliximab treatment. Eur J Pediatr. 2021;180:1581-91. https://doi.org/10.1007/s00431-021-03935-1

57. Alkan G EM, Oz SKT, Ergani AC, Emiroglu HH. Infliximab: A treatment option for multisystem inflammatory syndrome in children with ulcerative colitis? Turk Arch Pediatr. 2021;56:267-9.

https://doi.org/10.5152/TurkArchPediatr.2021.21057

58. Minen F, Hands C, Mustafa MR, Pienaar A, Lillie J. Thrombophilia in pediatric patients with multisystem inflammatory syndrome in children secondary to coronavirus disease 2019 supported on extracorporeal membrane oxygenation. Asaio J. 2021;67:7-11.

https://doi.org/10.1097/MAT.0000000000001270 